\title{
Geochemical indicators of paleo-seismicity based on the data of study of Fumarolnoe lake bottom sediments (Kamchatka, Uzon)
}

\author{
Ivan Kirichenko ${ }^{1, *}$, Nikolay Dobretsov ${ }^{2}$, Sergey Zhmodik $^{1}$, Elena Lazareva ${ }^{1}$, and Dmitry \\ Belyanin $^{1}$ \\ ${ }^{1}$ IGM SBRAS, Novosibirsk, 630090, Koptyug av., 3, Russian Federation \\ ${ }^{2}$ IPGG SBRAS, Novosibirsk, 630090, Koptyug av., 3, Russian Federation
}

\begin{abstract}
The distribution of chemical elements in bottom sediments of Fumarolnoe lake was obtained by XRFA. The mineral composition of the sediment was examined by SEM, XPA. Variations in contents of alkaline elements in the column of bottom sediments of the Fumarolnoe Lake have been studied using spectral methods (Wavelet and Fourier analyses). It has been established that concentrations of these elements change periodically, periods being correlated with periodic changes in seismic conditions of the present region
\end{abstract}

\section{Introduction}

Hot springs (lakes, geysers, mud and hot water pots) are unique natural ecosystems. Hydrothermal fluids and vapor-gas mixtures supplying these springs provide minor heat variations all-year inside a spring providing favorable conditions for development of thermophilic microorganisms. There is an opinion [1] that the chemical composition, temperature, and flow stream of hydrothermal waters supplying thermal springs usually are slightly varied in time in the scale of decades.

On the other hand, hydrothermal activity is a continuation or a part of volcanic activity and it continues during hundreds and thousands years gradually changing over time [2] that undoubtedly affect the chemical composition of hydrothermal fluids. The activation of hydrothermal activity with catastrophic consequences gives rise to significant changes of sedimentation conditions of thermal lakes and it is reflected in the material and microelement compositions of sediments.

It is known that changes in the concentration of some chemical elements from oceanic bottom sediments (i.e. isotope ratios) reflect changes in temperature of oceanic water [3]. The changes in concentration correlate with periodic changes of orbital parameters (precession, eccentricity) of the Earth. Conversely, stratified sediments of hot springs contain markers that identify the variability of geothermal and volcanic activities of the present region, and these sediments contain as well geochemical and biogenic markers of climatic changes.

* Corresponding author: iskirichenko@igm.nsc.ru 
The influence of both planetary and external factors on the regime of hot springs, in particular, geysers and mud volcanoes is proved in the rank of contributions [4]. It has been shown that gravitational impact of the Moon and the Sun can affect the seismic activity of our planet $[5,6]$ and it serves as a peculiar trigger for earthquakes and activation of volcanic activity.

These facts give hope that indicator elements with periodic or quasi-periodic variations can be revealed in sections of bottom sediments of thermal lakes, periods of which reflect changes in seismic activity of the region and these can be as a multiple of periods of changes in the main parameters of the system sun-moon-Earth.

The aim of the present work is to recognize regularities and quasi-variations in the distribution of chemical elements in bottom sediments of thermal lakes in volcanic regions.

\section{Subjects of investigation}

The thermal water body of the Fumarolnoe Lake located in the caldera of the Uzon volcano was chosen as the subject of investigation. The Uzon Caldera is located within the central Karymsk-Semyachinsk area of a graben-syncline in the Eastern Kamchatka at a distance of $300 \mathrm{~km}$ from Petropavlovsk-Kamchatsky. The caldera is a zone of ore formation with the mercury-antimony-arsenic mineralization occurring today [7].

The recent hydrothermal activity in the caldera is represented by outlets of superheated waters concentrated mainly on five large thermal fields with a total area of about $15 \mathrm{~km}^{2}$ [7]. The thermal fields are located along the fault passing through Kikhpinych, Uzon, and Taunshits volcanoes. The uniqueness of hydrothermal manifestations manifests a great variety of geochemical types of waters (chloride-sodium, sulfate-chloride, chloride-sulfatesodium, hydro-carbonate, and other types) focused on small squares. . In the opinion of many researches [2, 6, 7], the given variety is associated with the near-surface differentiation of initial high-temperature of chloride-sodium solutions coming from a deep fault.

Herewith, the following components: $\mathrm{CO}_{2}, \mathrm{H}_{2} \mathrm{~S}, \mathrm{CH}_{4}, \mathrm{Cl}, \mathrm{B}, \mathrm{Li}, \mathrm{Rb}, \mathrm{As}, \mathrm{Sb}, \mathrm{Hg}$ are considered as true deep, while thermal waters also contain significant amounts of metals $(\mathrm{Pb}, \mathrm{Zn}, \mathrm{Mo}, \mathrm{Cu})[7]$.

The most interesting is the ratio of $\mathrm{Li}: \mathrm{Rb}: \mathrm{Cs}=100: 10: 10$, which is unusual for both surface waters and the rocks. This ratio of alkaline elements is peculiar to high-temperature chloride-sodium-potassium highly mineralized waters with a complex gaseous composition, the composition of which are formed at the expense of a mantle source. Such waters are widespread in the Uzon caldera and other volcano active regions of the planet $[2]$.

\section{Methods and Samples}

A sediment column $(39 \mathrm{~cm})$ was selected in Lake Fumarole near the shore (N54 ${ }^{\circ} 30^{\prime} 7.40$ "E159 $\left.{ }^{\circ} 59^{\prime} 16.85^{\prime}\right)$, near a small funnel from which geothermal water flows. The column was taken using a stainless steel cylindrical sampler with a vacuum shutter with a diameter of $82 \mathrm{~mm}$ and a length of $40 \mathrm{~cm}$. The upper saturated with water, weakly consolidated layers of sediment $(0-10 \mathrm{~cm})$ were selected additionally using an aluminum cylinder. The substance of the column was packed in an airtight film immediately after the selection and then delivered to the laboratory. In the laboratory, the column was cut in length and samples of undeformed sediment were taken in small containers with preserving the structure of the sediment for the manufacture of polished sections. Part of the substance was dried and studied without polishing. The main minerals that form the sediment were 
identified using X-ray phase analysis (DRON 4 diffractometer, Cu-anode) at the IGM SB RAS (V.S. Sobolev Institute of Geology and Mineralogy). The composition and micromorphology of the minerals were studied on a MIRA 3 LMU (Tescan Orsay Holding) scanning electron microscope (SEM) with Aztec Energy / INCA Energy 450+ XMax 80 and INCA Wave 500 microanalysis systems, which allow studying nanoscale particles (Analytical Center IGM SB RAS). The chemical composition of bottom sediments was investigated by XRFA-SR scanning (X-Ray fluorescence analysis using synchrotron radiation)

\section{Results}

In May and September of 2012, solution was taken for analysis from a lake-let- IV of the Fumarolnoe Lake. It has been established that the solution parameters significantly change depending on a season. The total salt content was $226 \mathrm{mg} / \mathrm{l}$ in May, and it increased to 2520 $\mathrm{mg} / \mathrm{l}$ in September, the temperature increased from $20^{\circ} \mathrm{C}$ to $57^{\circ} \mathrm{C}$, and $\mathrm{pH}$ decreased from 5.7 to 4.2 . In the autumn, not only contents of macro - but also microelements in solution increased, and waters in the lake were characterized by high concentrations of Si (101000 lg/l), B (52000 lg/l), Br (6100 lg /l), As (3500 lg/l), I (183 lg/l), Li (6800 lg/l), Sr $(640 \mathrm{lg} / \mathrm{l}), \mathrm{Ba}(110 \mathrm{lg} / \mathrm{l})$, and $\mathrm{Cs}(480 \mathrm{lg} / \mathrm{l})$. The average sediment accumulation rate in the lake was $0,2 \mathrm{~mm} / \mathrm{yr}$.

Using XRFA-SR scanning, the distribution of major and trace elements $(\mathrm{K}, \mathrm{Rb}, \mathrm{Cs}, \mathrm{Li}$, $\mathrm{Ca}, \mathrm{Sr}, \mathrm{As}, \mathrm{Sb}, \mathrm{Ba}, \mathrm{Mo}, \mathrm{Ti}, \mathrm{Mn}, \mathrm{Fe}, \mathrm{Cu}, \mathrm{Zn}, \mathrm{Y}, \mathrm{Zr}, \mathrm{Nb}$ ) in the column (Fig.1) were measured. The distribution of chemical elements in the learned fragment of sediments $(0-$ $35 \mathrm{~cm}$ ) from the Fumarolnoe Lake was non-uniform with inclusion of layers significantly enriched with $\mathrm{Ca}, \mathrm{Sr}, \mathrm{As}, \mathrm{Sb}$, and $\mathrm{Mo}$. $\mathrm{Sb}$ and $\mathrm{As}$ are concentrated in some layers. The contents of As up to 4\% were revealed in layer No 3.1 (Fig. 1) at the depth of about $18 \mathrm{~cm}$. Below this layer, at the depth of $29 \mathrm{~cm}$, high contents of antimony (up to $0,8 \% \mathrm{Sb}$ ) were determined in layer No 6,. This fact is explained by the model of formation of the antimony-arsenic mineralization described earlier in papers [6].

The content of alkaline elements $(\mathrm{Li}, \mathrm{Rb}, \mathrm{Cs})$ in solution and bottom sediments of the Fumarolnoe Lake is high ( $\mathrm{Li}$ up to $100 \mathrm{ppm}, \mathrm{Rb}$ and $\mathrm{Cs}$ to $50 \mathrm{ppm}$ ) with anomalous $\mathrm{Li}: \mathrm{Rb}: \mathrm{Cs}$ ratios that are specific for thermal solutions only in volcanic regions of the planet.

The ratios of the rare alkaline elements in water of lake-let-IV of the Fumarolnoe Lake and in solutions from sources located on its shores were different: $\mathrm{Li}: \mathrm{Rb}: \mathrm{Cs}=100: 10: 7$ (in water of the lake with $\mathrm{Cs} / \mathrm{Rb}=0.7)$. This ratio in solutions in neighboring sources was $\mathrm{Li}: \mathrm{Rb}: \mathrm{Cs}=100: 18: 14$ with $\mathrm{Cs} / \mathrm{Rb}=0,8$.

The mineral composition of the sediment layers (according to the SEM), is represented by clay minerals: kaolinite and smectite, in the joint and pore space in which sulfide minerals (i.e. pyrite, antimonite, arsenic sulfides) are formed. A large number of diatoms are observed in the upper layers of the sediments (Fig. 2).

Variations in contents of alkaline elements in the column of sediments of the Fumarolnoe Lake were studied using spectral analytical methods (wavelet and Fourier analyses) (Fig. 3). It has been established that the statistically authentic periodic components in these signals (of the order of century and decades years) and periodic oscillations (of the order of 50 years) are not traced over the entire length of the column, but only in the time period 650-262 years A.D., which corresponds to the stage of "powerful endogenous regional catastrophism" [8]. The increase in volcanic activity from regional to planetary scales is characteristic of this period.

Thereby, the cycle of 50 years corresponds to the periods of occurrence of most significant tsunami (more than $5 \mathrm{~m}$ ) at the beginning of our era, traces of which were recorded in a coastal peat in the Kronotsky Bay [9] 
The reported study was funded, and Integration Project SB RAS N 51, and state assignment (№ 0330-2016-0011). The work/the part of the work relating to the measurement of spectra or the exposure of samples was done using the infrastructure of the Shared-Use Center "Siberian Synchrotron and Terahertz Radiation Center (SSTRC)" based on VEPP-3/VEPP-4M/NovoFEL of BINP SB RAS. The Ministry of Education and Science of The Russian Federation (project RFMEFI62117X0012) supported the work. Geochemical analyses were carried out at the Shared-Use Center for Multielemental and Isotope Studies, SBranch of the RAS.

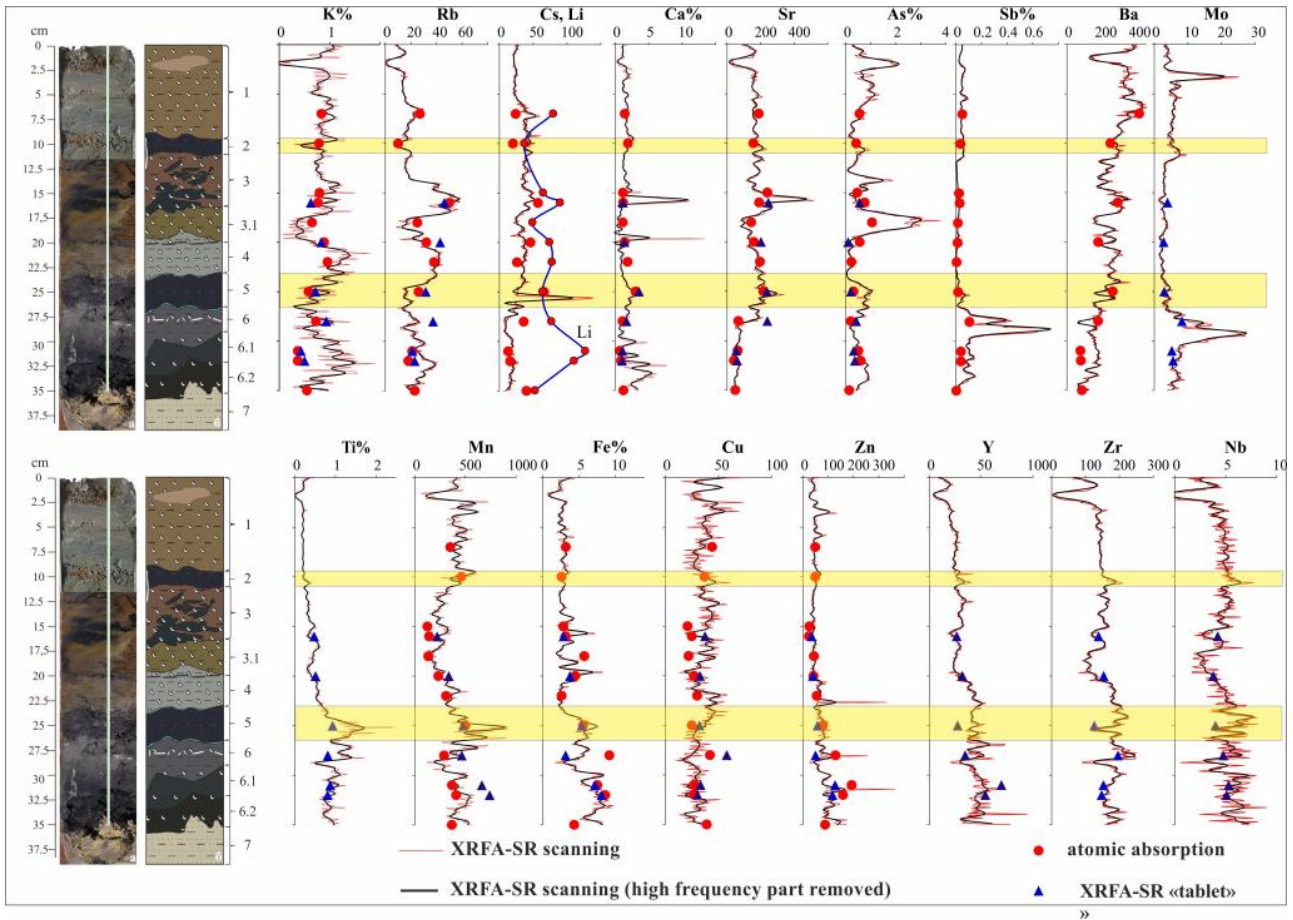

Fig. 1. Data of element analysis obtained using XRFA-SR. Colored rectangles show pyroclastic layers.

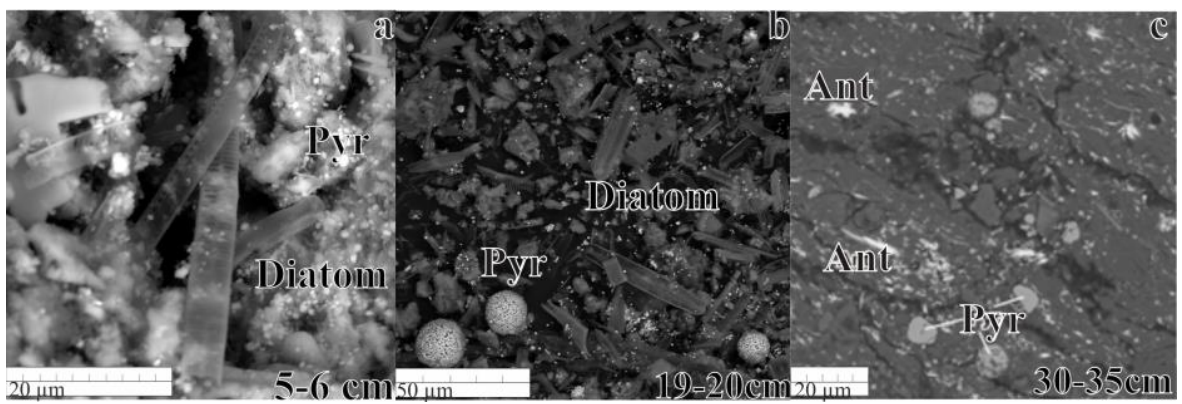

Fig. 2. The mineral composition of the bottom sediment lake Fumarolnoe (SEM data): (a) - pyrite in clay-diatom silt; (b) - pyrite framboid formation in the kaolinite-smectite substance; (c) - needle crystals and antimonite spherulites (Ant) and framboid of pyrite in the clayey substance (Pyr). 

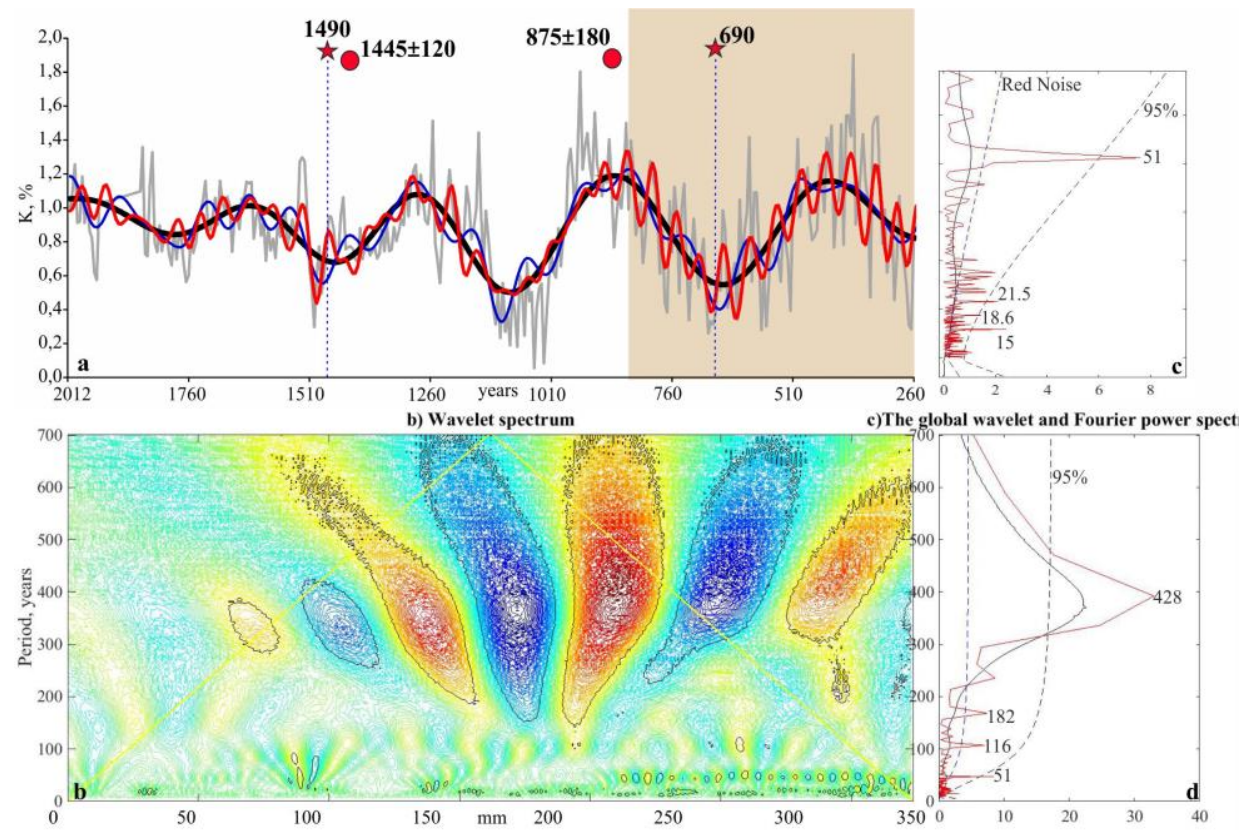

Fig. 3. Wavelet and Fourier spectrum of potassium distribution. a- gray line - potassium distribution along the section, black line (Discrete Wavelet Transform) - 400 years cycle, red (DWT) - 50 years periodicity. Stars - the time of formation of the pyroclastic horizons; circles - eruption of the Kikhpinych volcano according to [10]. b- Continuous Wavelet Transform spectrum. c, d - Fourier transform of the potassium distribution.

\section{References}

1. D. McColl, F. Forsyth, The limnology of a thermal lake: Lake Rotowhero, Hydrobiologia, 43 (3-4), 314 (1973)

2. G. Arsanova, The origin of the thermal waters of volcanic areas. Volcanology and Seismology, 6, 44 (2014) (in Russia)

3. C. Emiliani, Pleistocene temperatures. J. of Geology, 63 (6), 538 (1955)

4. S. Rinehart, Fluctuations in geyser activity caused by variations in Earth tidal forces, barometric pressure, and tectonic stresses. JGR, 77 (2), 342 (1972)

5. W. Hamilton, Tidal cycles of volcanic eruptions: fortnightly to 19 yearly periods. JGR, 78, 3363 (1973)

6. N. Dobretsov, About the frequency and different-scale factors of volcanic eruptions. Geology and Geophysics, 56, 2107 (2015) (in Russia)

7. S. Naboko, Volcanism, hydrothermal process and ore formation (M.: Nedra, 1974)

8. I. Melekestsev. 0-650 years - the stage of the strongest natural catastrophism of our era in Kamchatka. Volcanology and Seismology, 6, 3 (2003) (in Russia)

9. T. Pinegina, Geodynamics and volcanism of the Kuril-Kamchatka island-arc system, (2001)

10. O. Braytseva, G. Bogoyavlenskaya, E. Erlich, G. Pilipenko, G. Karpov, History of activity of the volcano Kikhpinych in the Holocene. Volcanology and Seismology, 6, 3 (1985) (in Russia) 